\title{
Myxozoan pathogens in cultured Malaysian fishes. I. Myxozoan infections of the sutchi catfish Pangasius hypophthalmus in freshwater cage cultures
}

\author{
K. Molnár ${ }^{1, *}$, C. Székely ${ }^{1}$, K. Mohamed ${ }^{2}$, F. Shaharom-Harrison ${ }^{2}$ \\ ${ }^{1}$ Veterinary Medical Research Institute, Hungarian Academy of Sciences, PO Box 18, 1581 Budapest, Hungary \\ ${ }^{2}$ Kolej Universiti Sains \& Teknologi Malaysia (KUSTEM), 2130 Kuala Terengganu, Terengganu, Malaysia
}

\begin{abstract}
Cage-cultured sutchi catfish Pangasius hypophthalmus (Sauvage, 1878), a favourite food fish in Southeast Asia, proved to be infected by 6 myxozoan species. Three species belonged to the genus Hennegoides ( $H$. berlandi, H. malayensis, and $H$. pangasii), 1 to Henneguya ( $H$. shariffi) and 2 to Myxobolus (M. baskai, and M. pangasii). Five myxozoans infected the gills and 1 was found on the spleen. Myxozoans infecting the gills were characterised by a specific site selection. $H$. shariffi sp. n. and $H$. berlandi sp. $\mathrm{n}$. formed plasmodia in the multi-layered epithelium of the gill filaments. Of the 2 vascular species $H$. pangasii sp. $\mathrm{n}$. developed in the gill arteries, while $M$. baskai sp. $\mathrm{n}$. infected the capillary network of the gill lamellae. Plasmodia of $H$. malayensis sp. n. were found inside the cartilaginous gill rays of the filaments. Large plasmodia of $M$. pangasii sp. n. were located in a groove of the spleen but they affected only the serosa layer covering the spleen.
\end{abstract}

KEY WORDS: Pangasius $\cdot$ Myxozoan infections $\cdot$ Henneguya $\cdot$ Hennegoides $\cdot$ Myxobolus $\cdot$ Site selection · Histology

Resale or republication not permitted without written consent of the publisher

\section{INTRODUCTION}

Freshwater fish culture in Southeast Asia is one of the fastest growing branches of agriculture. Traditional and endemic species including catfishes are cultured in ponds and cage systems (Csávás 1994). Pangasius hypophthalmus (Sauvage, 1878) is one of the most popular cultured species in Indo-Chinese countries. The original distribution of this fish, which is better known by its synonymous name $P$. sutchi, is the Mekong basin from where the fish was distributed to several Southeast Asian countries and China (Roberts \& Vidthayanon 1991, Cacot \& Lazard 2004), and more recently it was also introduced to Iran (Islam 2004). The technology of cage culture was developed by Cambodian fishermen. In addition, $P$. hypophthalmus fingerlings kept in aquaria are very popular among European pet fish hobbyists (authors' pers. comm).
Reports on the status of aquaculture in Malaysia, including catfish culture, were presented by Ang et al. (1989), Ang (1990), Khan et al. (1993) and Ong (1993). These authors reported that, in addition to Clarias batrachus and its hybrids, Pangasius spp. and a local catfish Hemibagrus nemurus (Valenciennes, 1840) (syn. Mystus nemurus) were the most commonly cultured fishes. Of these, P. hypophthalmus and $H$. nemurus proved to be the best adapted to cage cultures.

Little is known about parasitic infections of Pangasius spp. Data are mostly presented on their monogenean infections. Parisielle et al. (2002) described several Thaparocleidus species from the gills of $P$. bocourti, P. djambal and P. hypophthalmus. These authors reported that the latter monogeneans were strictly host specific. No paper has reported myxozoan infection of pangasiid fishes, although at a Hungarian local symposium in $2002 \mathrm{~F}$. Baska (unpubl.) reported that finger- 
lings of $P$. hypophthalmus imported from Thailand to be kept in aquaria were heavily infected by several Myxobolus spp.

There is only a single published work from Malaysia on myxozoan infections (Shariff 1982). This author made a complex morphological and pathological study on a myxozoan of Oxyeleotris marmoratus and described the species found as Henneguya shaharini.

The number of known myxosporeans is very high. The genera Myxobolus and Henneguya are the most abundant species. Landsberg \& Lom (1991) recorded 444 valid species of the genus Myxobolus, while Eiras (2002) mentioned 146 described species from the genus Henneguya. Little is known about myxozoan infections in Southeast Asia. Data on myxosporeans infecting fishes of the Indian fauna region (see Gussev 1969) are available mostly on several members of the genera Myxobolus and Henneguya, genera that have been described and recorded by Chakravarty (1939), Tripathi (1952), Lalitha-Kumari (1965, 1969), Sarkar (1985) and Sarkar et al. (1985). In addition to Shariff's (1982) work, myxozoan infections from Southeast Asian countries have been reported by Supamattaya et al. (2000), who described Sphaerospora epinepheli from the grouper Epinephelus malabaricus cultured in marine cages. Another Sphaerospora species, $S$. ojiroveci, was described by Lom \& Dyková (1997) from the pet fish Pangasius sutchi originating from Thailand, and $H$. longitudinalis, a type species of the new genus Hennegoides, was described by Lom et al. (1991) from Osphronemus gourami in Thailand. Further data on myxosporeans are found in the work of Ky (1971) from fishes of northern Vietnam, which according to Gussev (1969) belongs to the Amur-Chinese zoogeographical zone while the southern part of Vietnam, together with other Southeast Asian countries and India, belongs to the Indian fauna region.

The present paper describes 6 new myxozoan species (3 Hennegoides spp., 2 Myxobolus spp. and 1 Henneguya sp.) from net-cage cultured Pangasius hypophthalmus and discusses their site selection in the infected organs and their pathogenic effect.

\section{MATERIALS AND METHODS}

Sutchi catfish were collected from a cage culture on the Terengganu River close to Kuala Terengganu, Terengganu State, Malaysia. Altogether, 10 specimens of 16 to $19 \mathrm{~cm}$ and 10 specimens of 36 to $42 \mathrm{~cm}$ total length were dissected during a 2 wk period in late November and early December 2004. The investigations were aimed at studying myxosporean infections only. After surveying the skin and fins of the fish, the hemibranchia of the gills were excised, the abdominal cav- ity opened, and the intestine, spleen, liver, gonads and the kidneys separated.

Gill filaments of each hemibranchium were checked for myxozoan plasmodia under a Zeiss Stemi DV4 stereomicroscope. Plasmodia in filaments, lamellae or gill arches were differentiated according to Molnár (2002) to epithelial, vascular and chondroid locations. Plasmodia were carefully removed from the tissues and opened with a fine needle on a slide. Some of the spores obtained from mature plasmodia were studied in fresh smears under a Nikon Optiphot compound microscope. Other spores were saved for examination as permanent preparation, placed on slides and carefully covered by a coverslip containing a drop of melted glycerol-gelatine. Some of the plasmodia containing morphologically identical spores were fixed in 50 or $70 \%$ ethanol in vials for molecular biological examinations. The intestine was opened lengthwise, and after removal of the faeces the epithelial lining was surveyed under a stereomicroscope and scrapings were examined under a coverslip. The inner organs were inspected in toto, and pieces from them were studied in squash preparations under a compound microscope at a magnification of $\times 200$. Digital photos of fresh spores were taken with a Nikon Optiphot microscope connected to a computer. Measurements were taken from 25 fresh spores according to the guidelines suggested by Lom \& Arthur (1989). Additionally, photos of 25 spores were measured using the IMAGO ${ }^{\circledR}$ program.

Heavily infected hemibranchia of gills or some selected filaments were fixed in Bouin's solution for $4 \mathrm{~h}$, washed in $80 \%$ ethanol several times, embedded in paraffin wax, cut into 5 to $8 \mu \mathrm{m}$ thick sections and stained with haematoxylin and eosin. Microphotographs from the histological sections were taken with an Olympus DP-10 digital camera mounted on an Olympus BH-2 light microscope.

\section{RESULTS}

No myxosporean infection was found in fishes of the younger age group. All the 10 Pangasius hypophthalmus specimens examined measuring 36 to $42 \mathrm{~cm}$ in length harboured myxosporean plasmodia. All the gills of the large-sized fish were infected, while 6 of them showed infection in the spleen. No infection was found in other organs.

On microscopic examination, spores of 6 different myxozoans (3 Hennegoides spp., 2 Myxobolus spp. and 1 Henneguya sp.) were differentiated morphologically. Five species infected the gills while 1 Myxobolus sp. was found on the spleen. Most species had a characteristic location in the gills. All thFe species found proved to be new for science. Their description is as follows: 


\section{Henneguya shariffi sp. n.}

Host: Sutchi catfish Pangasius hypophthalmus

Location: Terengganu River

Site of infection: Gill filaments

Prevalence of infection: 7 out of 10 fish

Intensity: Moderate to intensive

Type material: Spores in glycerol-gelatine are deposited in the parasite collection of the Hungarian National History Museum. Collection number: HNHM69907.

Etymology: The species is named after M. Shariff, the well-known Malaysian fish pathologist who first described a Henneguya sp. in Malaysia.

Trophozoites: Ellipsoidal or round plasmodia of varying size up to $0.2 \times 0.5 \mathrm{~mm}$ in diameter were found at the tip and the lateral edge of the gill filaments inside the multi-layered epithelium.
Spores: Spores are typical for the genus Henneguya (Figs. 1A \& 2A). They are symmetric, elongated in shape with 2, relatively short caudal appendages, and with equal-sized polar capsules of elongated shape. The spore wall is thin and smooth and composed of 2 equal valves. The oral end of the spore body is blunt; the caudal end tapers and joins the caudal appendages. In a fresh state the length of the spore body is $10.3-11.9(11.7 \pm 1.26) \mu \mathrm{m}$, the width is $3.6-3.8$ $(3.71 \pm 0.07) \mu \mathrm{m}$, and the thickness is $3.6-3.8$ $(3.7 \pm 0.100) \mu \mathrm{m}$. The 2 polar capsules are elongated, blunt at the posterior end and taper anteriorly. Their length is $5.1-6.6(5.48 \pm 0.57) \mu \mathrm{m}$ and their width is $0.9-1.2(1.05 \pm 0.15) \mu \mathrm{m}$. The polar capsules open at the blunt end of the spore body. The polar filaments are coiled in 7 turns perpendicular to the long axis of the polar capsules. The length of the extruded filaments is 13.2-21 (15.35 \pm 3.99) $\mu \mathrm{m}$. The sporoplasm has a small iodinophilous vacuole. Caudal extensions are straight, continuously tapering and relatively short, 5.9-10.3 (7.54 \pm 2.0$) \mu \mathrm{m}$ in length.

Remarks: Spores of this species resemble the spores of Henneguya mystusia Sarkar, 1985, but differ from this species due to their shorter caudal appendages.

Histology: Plasmodia of this species started their development at the tip or at the edges of the gill filaments inside the multi-layered epithelium and formed relatively small plasmodia (Fig. 3A). Plasmodia were directly bordered by epithelial cells without a connective capsule. Developing plasmodia had a layer of sporogonic developmental stages in the ectoplasm and elongated spores in the centre.

\section{Hennegoides pangasii sp. $\mathrm{n}$.}

Host: Sutchi catfish Pangasius hypophthalmus

Location: Terengganu River

Site of infection: Large plasmodia in the gill filaments

Prevalence of infection: 6 out of 10 fish Intensity: Moderate

Type material: Spores in glycerolgelatine are deposited in the parasite collection of the Hungarian National History Museum. Collection number: HNHM69905.

Etymology: The species name is derived from that of its host.

Trophozoites: Trophozoites are large ellipsoidal plasmodia $0.2-0.5 \times 0.7-1.3 \mathrm{~mm}$ in size which are located in the central and apical region of the gill filaments.
Fig. 1. Henneguya, Hennegoides and Myxobolus spp. found in Pangasius hypophthalmus. (A) Henneguya shariffi sp. n. (B) Hennegoides pangasii sp. n. spore. (C) Spore body of $H$. pangasii sp. n. spore. (D) Hennegoides malayensis sp. n. spore. (E) Spore body of H. malayensis sp. n. (F) Hennegoides berlandi sp. n. spore. (G) Spore body of $H$. berlandi sp. n. spore. $(\mathrm{H})$ Myxobolus baskai spore with 2 caudal extensions at the posterior end. (I) $M$. pangasii spore in frontal view. (J) M. pangasii spore in lateral view. Scale bars $=10 \mu \mathrm{m}$ 

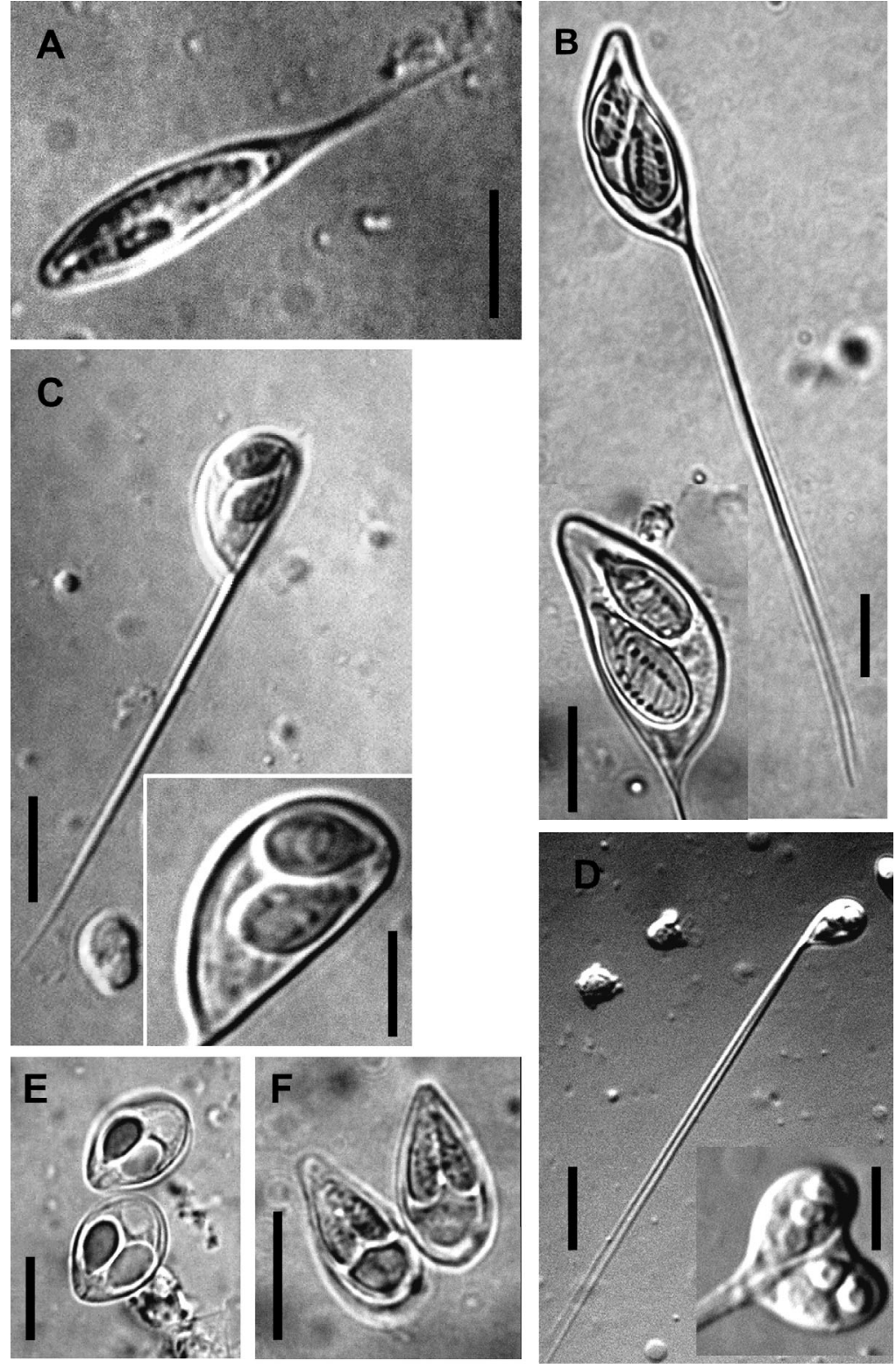

Fig. 2. Henneguya, Hennegoides and Myxobolus spp. spores found in Pangasius hypophthalmus. (A) Henneguya shariffi sp. n. Scale bar $=5 \mu \mathrm{m}$. (B) Hennegoides pangasii sp. $\mathrm{n}$. Scale bar $=10 \mu \mathrm{m}$ (inset: spore body of $H$. pangasii sp. n. Scale bar $=10 \mu \mathrm{m})$. (C) Hennegoides malayensis sp. n. Scale bar $=10$ $\mu \mathrm{m}$ (inset: spore body of $H$. malayensis sp. n. Scale bar $=5 \mu \mathrm{m}$ ). (D) Hennegoides berlandi sp. $\mathrm{n}$. Scale bar $=10 \mu \mathrm{m}$ (inset: still attached developing spore bodies of $H$. berlandi sp. Scale bar $=5 \mu \mathrm{m}$ ). (E) Fixed spores of $M$. baskai sp. n. without caudal appendages. Scale bar $=10 \mu \mathrm{m}$. (F) $M$. pangasii sp. $\mathrm{n}$. Scale bar $=10 \mu \mathrm{m}$

Spores: The mature spores are asymmetric in frontal view (Figs. 1B \& 2B). One side of the spore body is slightly vaulted while the other is strongly vaulted. The caudal appendages extend axially. The spore body tapers in both oral and caudal directions but at the anterior end it is rounded (Figs. 1C \& 2B inset). The length of the spore body is $24-30(27.3 \pm 1.73) \mu \mathrm{m}$, the width is $12-13.8(12.6 \pm 0.76) \mu \mathrm{m}$ and the thickness is $10.2-12(13.6 \pm 1.3) \mu \mathrm{m}$. The 2 polar capsules are elongated and droplike, different in size and have different locations in the cyst. The larger capsule located in the caudal part of the spore body measures $11.4-15(13.9 \pm 1.26) \mu \mathrm{m}$ in length and 6-7.2 (6.5 \pm 0.45$) \mu \mathrm{m}$ in width. The smaller capsule located close to the anterior end of the spore body at the more vaulted side of the spore wall measures $10-12.2(11.5 \pm 0.89) \mu \mathrm{m}$ in length and 4.8-6 $(5.1 \pm 0.46) \mu \mathrm{m}$ in width. The openings of the polar capsules do not extend to the anterior end of the spores. The threads of the polar filaments inside the larger polar capsule have 9 to 10 coils perpendicular to the longitudinal axis of the capsule; the number of coils in the smaller polar capsule is 7 or 8 . The extruded polar filaments are curled, measuring 48 to $54 \mu \mathrm{m}$ in length. The relatively small sporoplasm is located at the more vaulted part of the spore between the 2 polar capsules extending partly to the caudal edge. The straight, continuously tapering caudal extensions are 48-72 (64.5 \pm 9.24) $\mu \mathrm{m}$ long.

Remarks: The main features of this species bear the characteristics of the genus Hennegoides described by Lom et al. (1991). H. pangasii, however, differs from the type species $H$. longitudinalis due to its larger spore body and its long caudal extensions. In addition, in the polar capsule of $H$. pangasii the filamental turns are perpendicular to the long axis, while in the polar capsules of $H$. longitudinalis the threads are parallel to the long axis.

Histology: Elongated ellipsoidal plasmodia containing spores and sporogonic stages were located inside the afferent artery attaching closely to the cartilaginous gill rays of the filaments (Fig. 3B). The plasmodium was surrounded only by a single layer of host origin (presumably by the endothelium of the artery) which delimited the plasmodium from the cartilage on one side and from the subepithelial layer on the other side.

\section{Hennegoides malayensis sp. $\mathrm{n}$.}

Host: Sutchi catfish Pangasius hypophthalmus

Location: Terengganu River

Site of infection: Small plasmodia inside the cartilaginous gill rays 

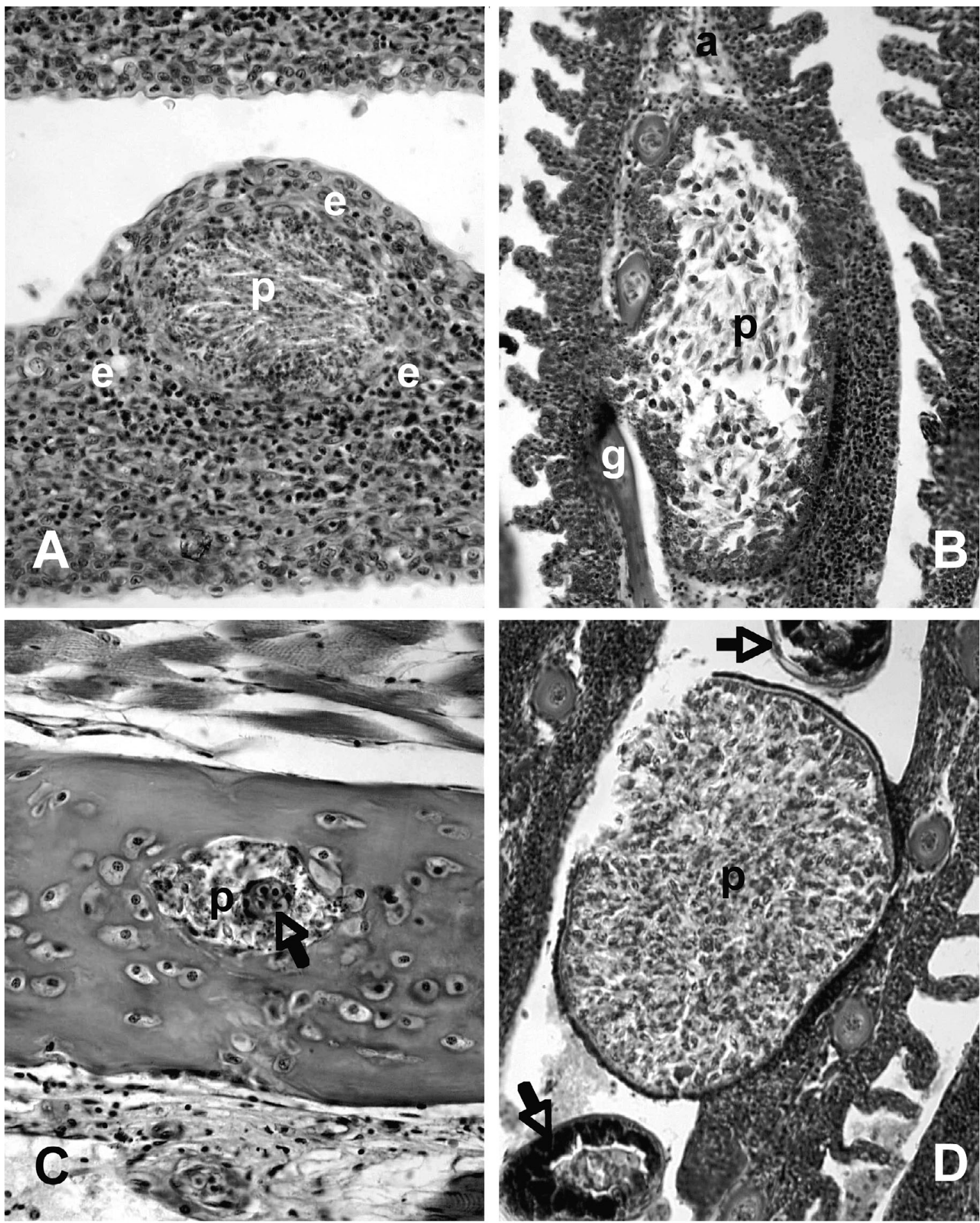

Fig. 3. Pangasius hypophthalmus. Haematoxylin and eosin stained histological sections of the gills. (A) Developing Henneguya shariffi sp. n. plasmodium (p) in the multi-layered epithelium (e) of the edge of a gill filament. The plasmodium contains sporogonic stages at the periphery and elongated spores in the centre. $\times 330$. (B) Hennegoides pangasii plasmodium (p) inside a gill artery (a). Inner part of the plasmodium is in close contact with the cartilaginous gill ray of the filament $(\mathrm{g})$; the other side is covered by the epithelium. $\times 206$. (C) Hennegoides malayensis plasmodium (p) in the cartilaginous gill ray of the filament. In the centre of the plasmodium there is an island of cartilage cells (arrow). $\times 450$. (D) Hennegoides berlandi plasmodium (p) with mature spores originating from the non-lamellar filament edge. On both sides of the plasmodium there are cross-sectioned monogenean specimens of the genus Thaparogyrus (arrows). $\times 206$ 
Prevalence of infection: 6 out of 10 fish

\section{Intensity: Moderate}

Type material: Spores in glycerol-gelatine are deposited in the parasite collection of the Hungarian National History Museum. Collection number: HNHM69904.

Etymology: The species name is derived from the name Malaysia.

Trophozoites: Trophozoites are either $40 \times 60 \mu \mathrm{m}$ elliptical or $40 \times 300 \mu \mathrm{m}$ elongated plasmodia in the posterior part of the cartilaginous gill rays.

Spores: The mature spores are asymmetric in frontal view (Figs. 1D \& 2C). One side of the spore body (Figs. 1E \& 2C inset) is strongly vaulted; the other one is straight. The oral end is rounded; the caudal end is slightly conspicuous. The length of the spore body is 12.5-14.4 (13.7 \pm 0.55$) \mu \mathrm{m}$, its width is $6.4-7.5(6.83 \pm$ $0.33) \mu \mathrm{m}$ and its thickness is $4.2-6.3(5.1 \pm 0.69) \mu \mathrm{m}$. The 2 polar capsules are drop-like and different in size; one of them located slightly behind the other. The anterior smaller capsule, located at the vaulted side of the spore, measures 5.1-6.2 (5.66 \pm 0.39$) \mu \mathrm{m}$ in length and $3-3.3(3.1 \pm 0.13) \mu \mathrm{m}$ in width. The posterior capsule located at the straight side of the spore measures 5.7-6.3 $(5.95 \pm 0.22) \mu \mathrm{m}$ in length and 3.1-3.5 (3.3 \pm 0.14$) \mu \mathrm{m}$ in width. Between the openings of the polar capsules there is a triangular intercapsular appendix with a length of about $1 \mu \mathrm{m}$. The polar filamental threads are coiled in 4 turns perpendicular to the longitudinal axis of the capsule. The extruded polar filaments measure $17-20 \mu \mathrm{m}$ in length. The relatively small sporoplasm is located at the vaulted and basal part of the spore. The caudal appendages which follow the line of the straight side are 36-40.5 (39.1 \pm 2.07$) \mu \mathrm{m}$ long.

Remarks: This species resembles Hennegoides longitudinalis and $H$. pangasii, but differs from $H$. pangasii by virtue of its more rounded anterior end and by the straight run of one side of the spore body. The size of $H$. malayensis is similar to that of $H$. longitudinalis, but it has longer caudal appendages, less elongated polar capsules and its filamental turns are perpendicular to the long axis.

Histology: Round (Fig. 3C) or elongated plasmodia were found inside the cartilaginous gill rays. The elongated plasmodia seemed to be composed of several ellipsoidal plasmodia. The plasmodia are not in contact with the chondrocytes; they are bordered directly by the cartilaginous material of the fin rays.

Hennegoides berlandi sp. $n$.

Host: Sutchi catfish Pangasius hypophthalmus

Location: Terengganu River

Site of infection: Elongated plasmodia at the edge of the gill filaments

Prevalence of infection: 6 out of 10 fish

Intensity: Moderate
Type material: Spores in glycerol-gelatine are deposited in the parasite collection of the Hungarian National History Museum. Collection number: HNHM-69906.

Etymology: The species is named after Dr. Björn Berland, the famous Norwegian fish parasitologist who actively promoted the work of this research team in KUSTEM.

Trophozoites: Trophozoites are 2 to $4 \mathrm{~mm}$ long plasmodia located alongside the edge of the gill filaments, or 0.5-1 mm large round plasmodia bulging out from the lateral edges of the filaments.

Spores: The mature spores are asymmetric in frontal view (Figs. 1F \& 2D) One side of the spore is strongly vaulted while the other one is straight. The oral end is rounded and the caudal end is conspicuous. The length of the spore body (Figs. 1G \& 2D inset) is 8-9 (8.5 \pm $0.54) \mu \mathrm{m}$, its width is $2.5-3(2.8 \pm 0.2) \mu \mathrm{m}$ and its thickness is $2.8-3.2(2.98 \pm 0.14) \mu \mathrm{m}$. The 2 polar capsules are drop-like and equal in size. The axis of the capsules runs at an angle of about $45^{\circ}$ to the straight side of the spore body. The length of the capsules is $2.5-3(2.8 \pm 0.27) \mu \mathrm{m}$ and the width is $1.5-2(1.84 \pm 0.23) \mu \mathrm{m}$. Between the openings of the polar capsules there is a very small round intercapsular appendix. The polar filaments are coiled in 4 turns perpendicular to the long axis of the polar capsules. The extruded polar filaments measure 14-18 (15.14 \pm 1.46$) \mu \mathrm{m}$ in length. The relatively small sporoplasm is located at the vaulted and basal part of the spore. There is a small round iodinophilous vacuole in the sporoplasm. The caudal appendages, which follow the line of the straight side, are long, measuring 40-50 (43.6 \pm 4.13$) \mu \mathrm{m}$.

Remarks: Hennegoides berlandi differs from $H$. malayensis and $H$. longitudinalis by virtue of its smaller size, and its more rounded spore body and polar capsules.

Histology: Both elongated and round plasmodia were located in the multi-layered epithelium of the non-lamellar edges of the filaments (Fig. 3D). Young trophozoites were mostly found at this location, but they also occurred in the lamellar part of the filaments in the multi-layered epithelium between 2 neighbouring lamellae (Fig. 4A). Myxobolus baskai sp. $n$.

Host: Sutchi catfish Pangasius hypophthalmus

Locality: Terengganu River

Site of infection: Gills

Prevalence of infection: 4 out of 10 fish

Intensity: Moderate

Type material: Spores in glycerol-gelatine are deposited in the parasite collection of the Hungarian National History Museum. Collection number: HNHM69908.

Etymology: The species is named after the Hungarian fish pathologist Ferenc Baska. 

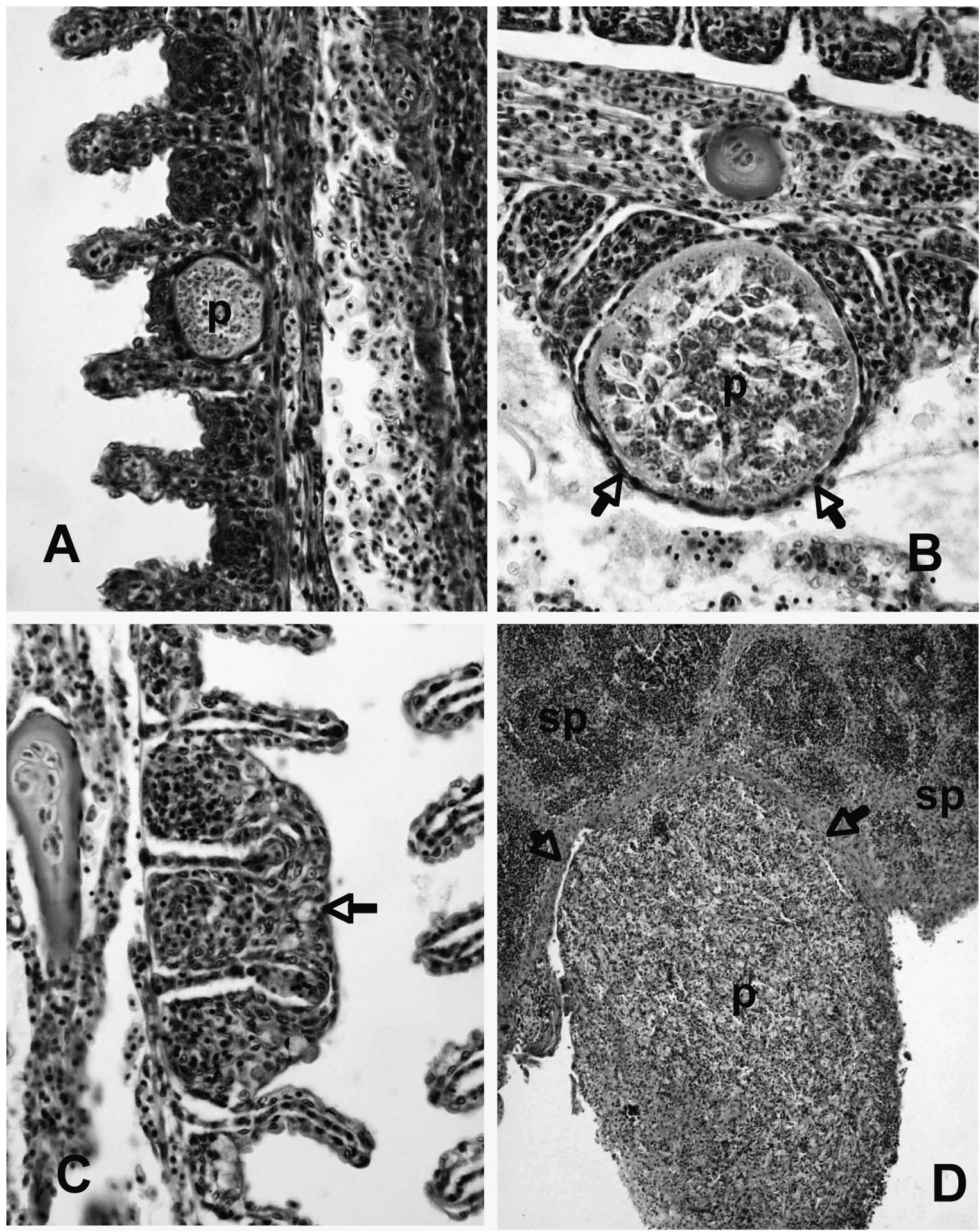

Fig. 4. Pangasius hypophthalmus. Haematoxylin and eosin stained histological sections of the gills. (A) Young Hennegoides berlandi trophozoite (p) developing in the multi-layered epithelium between 2 lamellae. $\times 450$. (B) Myxobolus baskai plasmodium (p) developing inside a gill lamella. The plasmodium is bordered by an endothelial and an epithelial layer of the lamellar capillary network (arrows). The neighbouring lamellae are compressed. $\times 450$. (C) Granulomatous inflammatory cells fill the place left by the released $M$. baskai spores between and over the gill lamellae (arrow). $\times 450$. (D) Large M. pangasii plasmodium (p) developing in the serosa (arrows) covering the spleen (sp). Part of the plasmodium sinks into the spleen; another part emerges over the 
Vegetative stages: Round plasmodia $0.5-1 \mathrm{~mm}$ in diameter develop mostly in the non-separated basal part of the filaments and are located between the dorsal and ventral part of filaments routing from the same place of the gill arch.

Spores: The mature spores are ovoid in frontal view, rounded at the posterior end and slightly tapered at the anterior end (Figs. $1 \mathrm{H} \& 2 \mathrm{E}$ ). In lateral view the spores are lemon-shaped. Spore valves are relatively thin, symmetrical and smooth. The sutural line is indistinct. No sutural markings were found. The spores measure 13.5-15 (14.2 \pm 059) $\mu \mathrm{m}$ in length, 10.5-11 (10.64 \pm $0.37) \mu \mathrm{m}$ in width and 6.5-7.2 (6.83 \pm 0.39$) \mu \mathrm{m}$ in thickness. There is a relatively large, triangular intercapsular appendix 1.5-2 $\mu \mathrm{m}$ in length, residing on the thickened anterior part of the spore valve (Figs. $1 \mathrm{H} \& 2 \mathrm{E}$ ). The 2 polar capsules are drop-like in shape, equal in size and measure 5.5-7 (6.35 \pm 0.52$) \mu \mathrm{m}$ in length and $3.5-5(4.33 \pm 0.5) \mu \mathrm{m}$ in width. Polar capsules slightly converge toward the anterior end of the spores, and open at the base of the intercapsular appendix. Polar filaments are coiled obliquely with 5 or 6 turns in the polar capsule, at an angle of $45^{\circ}$ to the longitudinal axis of the capsules. The extruded filaments measure $45-50(47.83 \pm 2.04) \mu \mathrm{m}$ in length. Inside the relatively small sporoplasm the 2 nuclei and the iodinophilous vacuole are well discernible. Attached to the posterior end of the spores there is 1 (in frontal view), in some spores 2 (in lateral view), approximately $10 \mu \mathrm{m}$ long and $5 \mu \mathrm{m}$ wide caudal appendages differing in nature from the spore valves, which are indiscernible in glycerol-gelatine preparations.

Remarks: Due to the presence of caudal appendages on the posterior end of the spores, this species could be classified to the genera Unicauda Davis, 1944 or Dicauda Hoffman and Walker, 1978, but the present authors think that the non-chitinous mucous structures are characteristic only for the species and not for the genus. In addition to the presence of the appendages, this species differs from the known species by the thickened anterior part of the spores.

Histology: Plasmodia were located inside the capillary network of the gill lamellae surrounded by a single endothelial and epithelial layer of the lamellae (Fig. 4B).

Myxobolus pangasii sp. $n$.

Host: Sutchi catfish Pangasius hypophthalmus

Locality: Terengganu River

Site of infection: Spleen

Prevalence of infection: 7 out of 10 fish

Intensity: Moderate

Type material: Spores in glycerol-gelatine are deposited in the parasite collection of the Hungarian National History Museum. Collection number: HNHM-69909.
Etymology: The species name is derived from that of its host.

Vegetative stages: Round plasmodia or some closely attached plasmodia bulging above the surface by 1-3 mm were located in the serosa layer of the spleen.

Spores: The mature spores are of ovoid shape in frontal view, rounded at the posterior end and tapered at the anterior end (Figs. 1I \& 2F). In lateral view the spores are lemon-shaped (Fig. 1J). Spore valves are relatively thin, symmetrical and smooth. The sutural line is distinct. No sutural markings were found. The spores measure 13.5-15 (14.3 \pm 0.48$) \mu \mathrm{m}$ in length, $6-7.8(7.03 \pm 0.58) \mu \mathrm{m}$ in width and $4-5(4.6 \pm 0.54) \mu \mathrm{m}$ in thickness. No intercapsular appendix was found, but the spore walls thickened at the anterior part. The 2 polar capsules are elongated, equal in size and measure $6-7.5(6.42 \pm 0.54) \mu \mathrm{m}$ in length and 1.4-2 (1.68 \pm 0.22) $\mu \mathrm{m}$ in width. Polar capsules slightly converge toward the anterior end of the spores, and open relatively far from the anterior end. Polar filaments are coiled with 5 turns in the polar capsule; the coiled threads are perpendicular or slightly oblique to the longitudinal axis of the capsules. The extruded filaments measure $24-27(25 \pm 1.09) \mu \mathrm{m}$ in length. Inside the relatively small sporoplasm the 2 nuclei and the iodinophilous vacuole are well discernible.

Remarks: Based on the shape of the spores Myxobolus pangasii resembles some common species such as $M$. macrocapsularis and $M$. carassii but differs from them by virtue of the anterior thickening of the spore valves.

Histology: Plasmodia were found in the serosa covering the spleen. Some of the plasmodia were sunken in the parenchyma of the spleen, while others grew over the surface of this organ. Despite the close contact, plasmodia were always delimited from the parenchyma of the spleen by the serosa (Fig. 4D).

Pathogenicity: No general alterations were found in the gills and the spleen. In the case of Hennegoides pangasii, local changes consisted of dilatation of the afferent artery of the filament, encapsulation of the plasmodium by an endothelial layer, atrophied respiratory lamellae around the site of the plasmodium and aneurysmal dilatation of the artery. In lamellar infection with Myxobolus baskai the function of the lamella was blocked by the growing plasmodium, and the large cyst compressed the neighbouring lamellae. At a later stage of repair, granulomatous inflammatory reaction was seen at the site of invasion (Fig. 4C). In the case of epithelial infection with Henneguya shariffi and $H$. berlandi, local proliferation of the epithelium around the cyst and compression of the neighbouring lamellae and filaments were found.

Only degenerative changes were seen in the cartilaginous gill rays in Hennegoides malayensis infection, 
which resulted in the formation of holes around the spores inside the cartilage. In the case of splenic infection with Myxobolus pangasii, dilatation of the capillaries and an increased number of red blood cells in the serosa layer between the spleen and the large plasmodium were the most remarkable histological changes.

Co-infections: In addition to myxozoan infections, only a few parasites belonging to other groups were found, of which Thaparocleidus spp. were the most common (Fig. 3D).

\section{DISCUSSION}

Although an earlier report on pet fish specimens imported to Hungary (F. Baska unpubl.) has already indicated the frequent occurrence of myxozoan infection in Pangasius hypophthalmus, the investigations presented in this paper give further evidence that heavy myxozoan infections can develop in this favourite food and aquarium fish. Dissections of cagecultured specimens have demonstrated that $P$. hypophthalmus is infected by at least 6 myxozoan species. Gills proved to be the most infected organ, in which 5 species were found. The occurrence of Henneguya spp. on the gills of tropical catfishes is rather common. In recent years, several new species have been described from Indian and African fishes (Sarkar 1985, Fomena \& Bouix 1996, Kpatcha et al. 1997). Up to this time, however, the genus Hennegoides was represented only by a single species, $H$. longitudinalis, the parasite of the gourami (Lom et al. 1991). The finding of 3 new Hennegoides species in the gills of $P$. hypophthalmus indicates that further examinations could reveal the occurrence of several other members of this genus in Southeast Asia. These examinations also prove that a fish can be infected simultaneously with 6 different species belonging to 3 genera. Of the examined organs, only the gills and the spleen proved to be infected. All species found had a typical location in the infected organs. The site selection and specific locations of myxozoans infecting the gills have been studied in detail by Molnár (2002). This author differentiated species infecting blood vessels (vascular type), the epithelium, the connective tissue and the cartilage. Within these types he selected species that preferried the filaments, the lamellae or the gill arches as site. Most of the species found during the present investigations could be assigned to the categories suggested by Molnár (2002). Out of the 5 new species infecting the gills, 2 species (Henneguya shariffi, Hennegoides berlandi) had a typical epithelial location, 2 others (Hennegoides pangasii, Myxobolus baskai) developed in the blood vessels, and Hennegoides malayensis selected the cartilage as typical location. H. shariffi, which was located in the multi-layered epithelium, infected mostly the tip and edges of the filaments. $H$. berlandi preferred the same sites but formed larger plasmodia than did $H$. shariffi. $H$. berlandi had characteristic elongated plasmodia running from the tip toward the base of the filaments inside the multilayered epithelium of the filament edge. H. malayensis proved to be a chondrophilic species located inside the cartilaginous filament rays. $H$. pangasii had a vascular location inside the afferent artery. $M$. baskai was also characterised by a specific vascular location. The plasmodia of this latter species developed at the non-separated basal parts of filaments where an outer and an inner filament originating from the gill arch unite. Histological studies revealed that the young trophozoites started their development in the capillary network of the lamellae. M. pangasii was always found on the surface of the spleen and never in other locations in the abdominal cavity. Despite this specific location, $M$. pangasii cannot be regarded as a parasite of the spleen, as the plasmodia never came into contact with the parenchyma of the spleen but infected only the serous membrane covering the spleen.

The taxonomic position of Myxobolus baskai raises several questions. Due to the presence of caudal appendages on examination in a fresh state, this species differs from most of the known Myxobolus species and could be classified into the genera Unicauda or Dicauda. According to Lom \& Dyková (1992), the members of these genera have Myxobolus-type spores with appendages adhering to the posterior part of the shell valves, but these appendages are made up of a different material than the spore valve. In our case, 1 or 2 appendages were seen at the caudal end, depending on the position of the spores. The presence of these appendages could not be seen in fixed preparations. Although there are more than 20 Unicauda and Dicauda spp., and Cone \& Melendy (2000) listed 16 described Unicauda spp., the validity of the latter genera is still questionable because of the uncertain keys used for determination. We think that mucous envelopes, membranaceous envelopes and non-sclerotised appendages are useful tools for species identification but they must not be used for creating or accepting new genera. Therefore, we classified our species into the genus Myxobolus Buetschli.

The intensity of infection varied in the fish specimens examined in this survey. During the short period examination no disease symptoms were recorded and we cannot give data on the pathogenicity of the myxozoan infections. However. the large number of myxozoan species found, the intensive infection of some fish specimens, and the local changes seen around the parasites 
suggest the possibility that further intensification of the culture might produce evidence of more severe symptoms and losses.

Acknowledgements. The authors thank Dr. Björn Berland for technical help and Ms. Seem Yee Wong for her help in collecting parasites. We are grateful to Ms. Györgyi Ostoros for the histological work. The work was done in a Hungarian-Malaysian co-operation within the TÉT-MOSTE (No. 1) Agreement and it was partially financed by the Hungarian Scientific Research Fund (OTKA), project nos. T 45891 and T 42464.

\section{LITERATURE CITED}

Ang KJ (1990) Status in aquaculture in Malaysia. In: Joseph MM (ed) Aquaculture in Asia. Asian Fisheries Society, Indian Branch, Mangalore, p 265-279

Ang KJ, Gopinath R, Chua TE (1989) The status of introduced fish species in Malaysia. In: De Silva SS (ed) Exotic aquatic organisms in Asia. Proceedings of the Workshop on Introduction of Exotic Aquatic Organisms in Asia. Asian Fish Soc Spec Publ 3, Asian Fisheries Society, Manila, p 71-82

Cacot P, Lazard J (2004) Domestication of two species of pangasid catfish family in the Mekong delta. Prod Anim (Paris) 17:195-198

Chakravarty MM (1939) Studies on Myxosporidia from the fishes of Bengal, with a note on myxosporidian infection in aquaria fishes. Arch Protistenkd 92:169-178

Cone DK, Melendy JS (2000) Infections of Unicauda clavicauda (Kudo, 1934) (Myxozoa) in the skin of Notropis hudsonicus (Cyprinidae) from Montana, with a synopsis of the genus Unicauda Davis, 1944. Folia Parasitol 47:273-278

Csávás I (1994) Status and perspectives of culturing catfishes in East and Southeast Asia. FAO Aquacult Newsl (FAN) 8: $1-10$

Eiras JC (2002) Synopsis of the species of the genus Henneguya Thélohan, 1892 (Myxozoa: Myxosporea: Myxobolidae). Syst Parasitol 52:43-54

Fomena A, Bouix G (1996) New species of Henneguya Thélohan, 1892 (Myxozoa: Myxosporea) parasites of freshwater fishes in Cameroon. J Afr Zool 110:43-53

Gussev AV (1969) The history of the fauna and adhesive adaptations of freshwater monogeneans from Eurasia and North America. Parasitol Sbornikh 24:106-127 (in Russian)

Islam A (2004) Studies on some aspects of biology with special reference to induced spawning of Thai pangas (Pangasius sutchi Fowler, 1937). Iran J Fish Sci 4:45-66

Khan MS, Ang KJ, Ambak MA, Saad CR (1993) Optimum dietary protein requirement of a Malaysian freshwater catfish, Mystus nemurus. Aquaculture 112:227-235

Kpatcha TK, Faye N, Diebakate C, Fall M, Toguebaye BS (1997) Nouvelles esèpces d'Henneguya Thelohan, 1895 (Myxozoa, Myxosporea) parasites des poisons marins du

Editorial responsibility: Wolfgang Körting,

Hannover, Germany
Sénégal: étude en microscopie, photonique et électronique. Ann Sci Nat Zool Biol Anim 18:81-91

Ky H (1971) Some freshwater myxosporean species from North Vietnam. Acta Protozool 8:283-298 (in Russian)

Lalitha-Kumari PS (1965) On a new species of Henneguya (Protozoa: Myxosporidia) from Indian freshwater fish, Ophiocephalus gachua. Riv Parassitol 26:79-84

Lalitha-Kumari PS (1969) Studies on parasitic protozoa (Myxosporidia) of freshwater fishes of Andhra Pradesh, India. Riv Parassitol 30:154-225

Landsberg JH, Lom J (1991) Taxonomy of the genus Myxobolus (Myxobolidae: Myxosporea): current listing of species and revision of synonyms. Syst Parassitol 18:165-186

Lom J, Arthur JR (1989) A guideline for preparation of species description in Myxosporea. J Fish Dis 12:151-156

Lom J, Dyková I (1992) Protozoan parasites of fishes. Elsevier, New York

Lom J, Dyková I (1997) Light and electron microscope observations on Sphaerospora ojiroveci n. sp. (Myxozoa) from the kidney of Pangasius sutchi (Teleostei). Eur J Protistol 33:444-451

Lom J, Tonguthai K, Dyková I (1991) Hennegoides longitudinalis $\mathrm{n}$. gen. n. sp., a myxosporean parasite of Osphronemus gourami from Thailand. Dis Aquat Org 11:141-145

Molnár K (2002) Site preference of myxosporeans in the gill. Dis Aquat Org 48:197-207

Ong KS (1993) Aquaculture development in Malaysia in the 1990s. Risalah Perikanan Bil 51. Jabatan Perikanan Kementerian Pertanian Malaysia, Kuala Lumpur

Parisielle A, Lim LSH, Lambert A (2002) Monogeneans from Pangasiidae (Siluriformes) in Southeast Asia: III. Five new species of Thaparocleidus Jain, 1952 (Ancylodiscoidae) from Pangasius bocourti, P. djambal and P. hypophthalmus. Parasite 9:207-217

Roberts TR, Vidthayanon C (1991) Systematic revision of the Asian catfish family Pangasiidae, with biological observations and descriptions of three new species. Proc Acad Nat Sci Phila 143:97-144

Sarkar NK (1985) Myxosporidian Henneguya mystusia sp. n. (Myxozoa: Myxosporea) from the gills of a freshwater teleost fish Mystus sp. Acta Protozool 24:55-58

Sarkar NK, Mazumder SK, Pramanik A (1985) Observation of 4 new species of myxosporidia (Myxozoa) from channid (Ophiocephalid) fishes of West Bengal, India. Arch Protistenkd 130:289-296

Shariff M (1982) Henneguya shaharini sp. nov. (Protozoa: Myxozoa), a parasite of marble goby, Oxieleotris marmoratus (Bleeker). J Fish Dis 5:37-45

Supamattaya K, Fischer-Scherl T, Hoffmann RW, Boonyaratpalin S (2000) Sphaerospora epinepheli n. sp. (Myxosporea: Sphaerosporidae) observed in grouper (Epinephelus malabaricus). J Protozool 38:448-454

Tripathi YR (1952) Studies on parasites of Indian fishes. Protozoa: Myxosporidia together with a check-list of parasitic protozoa described from Indian fishes. Rec Indian Mus 50: $63-88$

Submitted: March 21, 2005; Accepted: October 11, 2005 Proofs received from author(s): January 20, 2006 